\title{
Falha da transferência de imunidade passiva em cordeiros mestiços (Santa Inês x Dorper) e estudo do proteinograma do nascimento até o desmame
}

\author{
Failure of passive immunity transfer in crossbred lambs (Santa Inês x Dorper) and \\ proteinogram study from birth until waned
}

\author{
Joselito Nunes COSTA ${ }^{1}$; Débora de Fátima Matias da SILVA ${ }^{2}$; Carla Caroline Valença de LIMA; \\ Thiago Sampaio de SOUZA ${ }^{3}$; Alexandre Lôpo ARAÚJO'; Antônio Oliveira COSTA NETO ${ }^{5}$; \\ Maria Angela Ornelas de ALMEIDA ${ }^{1}$ \\ ${ }^{1}$ Centro de Ciências Agrárias, Ambientais e Biológicas da \\ Universidade Federal do Recôncavo da Bahia, Cruz das Almas - BA, Brasil \\ ${ }^{2}$ Mestre em Ciência Animal nos Trópicos da Universidade Federal da Bahia, Salvador - BA, Brasil \\ ${ }^{3}$ Doutorando(a) em Ciência Animal nos Trópicos da Universidade Federal da Bahia, Salvador - BA, Brasil \\ ${ }^{4}$ Médico Veterinário Autônomo, Salvador - BA, Brasil \\ ${ }^{5}$ Departamento de Biologia da Universidade Estadual de Feira de Santana, Feira de Santana - BA, Brasil
}

\begin{abstract}
Resumo
Analisou-se a ocorrência da Falha de Transferência da Imunidade Passiva (FTIP) em 45 cordeiros nascidos de ovelhas saudáveis e pluríparas. Estes animais foram acompanhados do nascimento até o desmame (90 dias), por meio de avaliações físicas, do hemograma, determinação de proteínas séricas totais e seu fracionamento eletroforético entre 24-72h pós-nascimento (p.n.), aos 7, 15, 30, 60 e 90 dias de idade (quando era realizada a desmama). Adotando-se o ponto de corte para proteínas séricas totais da ordem de 4,5g/dL, obteve-se a ocorrência de FTIP de $24,4 \%$ (11 animais). Os cordeiros com FTIP apresentaram menores valores $(\mathrm{p}<0,05)$ de proteínas séricas, albumina, alfaglobulina, betaglobulina 1 e gamaglobulinas entre 24-72h p.n. quando comparados aos dos 34 animais que não tiveram FTIP. Porém, a partir dos sete dias de vida não foram observadas diferenças significativas destas variáveis entre os grupos, 0 que indica um processo de produção ativa de proteínas pelo grupo com FTIP.
\end{abstract}

Palavras-chave: Colostro. Imunidade. Ovinos.

\begin{abstract}
It was analyzed the occurrence of the failure of passive transfer (FTIP) of the immunity 45 born lambs of healthy and pluriparous ewes. These animals were accompanied from the birth to the wean (90 days), when clinical evaluations were accomplished, hemogram, determination of total serum proteins and their electrophoretic fractions, 24-72h after the birth, to the 7, 15, 30, 60 and 90 days of age (at the same time of the wean). Adopting the cut point for total serum proteins of the order of $4.5 \mathrm{~g} / \mathrm{dL}$, it was obtained the occurrence of FTIP of $24.4 \%$ (11 animals). The lambs with FTIP presented lowers values $(\mathrm{p}<0.05)$ of serum proteins, albumin, alpha-globulin, beta-globulin 1 and gamma globulins when compared to the 34 animals that have no FTIP. However, from 7th days of life it was not observed significant differences of these variables between groups, indicating the occurrence of a process of active production of proteins by group FTIP.
\end{abstract}

Keywords: Colostrum. Immunity. Sheep.

\section{Introdução}

Os cordeiros adquirem proteção imunológica após o nascimento, através da ingestão do colostro, em virtude do tipo de placenta que na ovelha é sindesmocorial, e por isso impermeável. Este fato faz com que os neonatos desta espécie, ao nascerem, sejam hipogamaglobulinêmicos e dependam dos anticorpos absorvidos do colostro. Este processo,
Correspondência para:

Joselito Nunes Costa

Av. Adhemar de Barros, 500, Ondina, Salvador, BA

CEP: $40.170-110$

e-mail: joselitonc@yahoo.com.br

Recebido: 08/12/2011

Aprovado: 02/04/2013 
denominado de transferência de imunidade passiva, é de extrema importância para a proteção neonatal ${ }^{1}$.

A falha da transferência de imunidade passiva (FTIP) é definida como a ausência de adequada concentração das imunoglobulinas plasmáticas, obtidas passivamente através da absorção do colostro, e é diagnosticada entre 24 e 48 horas após o nascimento ${ }^{2}$. Donovan et $\mathrm{al}^{3}{ }^{3}$, referem que a condição de FTIP é responsável pelo aparecimento de septicemia neonatal e por um aumento na incidência e severidade de casos de pneumonia e diarreia entre outras afecções, elevando significativamente a taxa de mortalidade de ruminantes recém-nascidos e também comprometendo o desempenho produtivo em idades posteriores. Estima-se que 35\% dos bezerros leiteiros sejam acometidos pela FTIP. Esta condição também ocorre em cordeiros, cabritos e suínos, devendo ser considerada como um importante problema econômico importante a ser observado nos rebanhos ${ }^{4}$. Bekele, Otesile e Kasali ${ }^{5}$, estudando a ocorrência de FTIP em 628 cordeiros, verificaram que $15,3 \%$ e $1,8 \%$ apresentaram respectivamente falha parcial ou total de transferência de imunoglobulinas maternais, e destes, $54,5 \%$ vieram a óbito, ressaltando assim o grande impacto negativo que a FTIP produz na sobrevivência dos cordeiros.

Para diagnosticar a FTIP, monitorar a eficiência de um manejo de fazenda, avaliar animais a serem adquiridos ou determinar as taxas de falha de transferência da imunidade passiva em pesquisas de doenças neonatais, há uma série de testes, que podem ser realizados das primeiras horas até os primeiros dias de vida, o que é possível por causa da meia-vida relativamente longa da $\operatorname{IgG}^{6,7}$. A proteína sérica total mensurada pelo método do biureto ${ }^{8}$ tem sido utilizada com frequência como um método indireto destinado a estimar a concentração de imunoglobulinas no soro. A avaliação da aquisição de imunidade passiva também pode ser realizada pelo fracionamento eletroforético das proteínas séricas ou plasmáticas ${ }^{9}$, o que permite a quantificação da fração gamaglobulina, que inclui as imunoglobulinas maternais absorvidas ${ }^{6}$. A extensa variabilidade nas concentrações de imunoglobulinas séricas nos indivíduos, decorrentes das influências de diversos fatores externos, dificulta a determinação de valores limites para o estabelecimento do diagnóstico da FTIP. Garry, Aldridge e Adams ${ }^{10}$ afirmaram que valores específicos para o estabelecimento do diagnóstico de FTIP podem levar a suposições incorretas, pois o conceito de falha na transferência da imunidade passiva não deve ter aplicação absoluta, uma vez que a defesa orgânica do neonato insere-se em uma equação mais complexa na qual a concentração de imunoglobulinas é somente um fator.

Turquino, Flaiban e Lisbôa ${ }^{11}$ referem que existem poucas referências sobre as taxas de mortalidade em ovinos em regiões de clima semiárido do Brasil. No Estado do Piauí, a mortalidade de cordeiros foi de $15,18 \%$, ocorrendo maior taxa de mortalidade entre os nascidos de partos gemelares $(24,74 \%)$ do que nos provenientes de parto simples $(12,13 \%)^{12}$. Nóbrega Jr. et al. ${ }^{13}$, destacam a ausência de trabalhos sobre a taxa de mortalidade neonatal em ovinos criados de forma extensiva, com baixa tecnologia. Na região Nordeste, no entanto, fazendeiros citam percentuais superiores a 50\%. Chaarani, Robinson e Jhonson ${ }^{14}$ encontraram taxas de mortalidade de cordeiros da ordem de 46,3 a $51,5 \%$ tendo como principal causa de óbito o complexo inanição/hipotermia.

O presente trabalho avaliou a ocorrência da falha da transferência da imunidade passiva em cordeiros mestiços (Santa Inês x Dorper), em uma propriedade com um determinado sistema de manejo de ovinocultura, verificando a sua influência no proteinograma do nascimento até o desmame (aos 90 dias de idade). 


\section{Materiais e Métodos}

A pesquisa foi realizada em uma fazenda localizada na região do recôncavo baiano, cuja atividade principal é a ovinocultura comercial. Foram utilizados 45 cordeiros, machos e fêmeas, com variados graus de sangue (meio-sangue a três-quartos dorper) nascidos de mães pluríparas com idade média de três anos. As ovelhas do experimento tiveram sua condição de saúde avaliada pelo exame físico segundo Pugh ${ }^{15}$ e complementares (hemograma ${ }^{16}$ e parasitológico de fezes ${ }^{17}$ ). Os cordeiros foram acompanhados do nascimento até os 90 dias de idade.

As matrizes eram mantidas sob manejo de pastejo rotacionado em pastagens de Brachiaria decumbens, B. brizanta e B. humidícula durante o dia, sendo recolhidas para o curral no fim da tarde, onde recebiam sal mineral comercial ad libitum. A propriedade adotava manejo reprodutivo de monta controlada. Aproximadamente um mês antes do parto, as ovelhas eram separadas do rebanho e alocadas em piquete e curral maternidade, durante o dia e à noite, respectivamente. Após o parto, era realizada a cura do umbigo do cordeiro com solução de iodo a $10 \%$, sendo então a ovelha e seu cordeiro mantidos no aprisco durante as primeiras 24 horas pós-parto. Nos dois dias subsequentes tanto a ovelha como os cordeiros permaneciam juntos no piquete maternidade durante o dia e eram presos no final da tarde. Após este período, os cordeiros eram liberados juntamente com suas mães durante o dia, sendo recolhidos em currais separados durante a noite. Os cordeiros submetidos a este manejo nasciam no piquete ou no curral maternidade, de parto natural sem observação, e permaneciam com as matrizes mamando o colostro ad libitum. O curral destinado a alocar os cordeiros era equipado com campânulas de aquecimento e, neste local, os cordeiros recebiam ração complementar (composta por milho, farelo de soja e farelo de trigo) fornecida diariamente até o desmame (aos 90 dias de idade). Para estabelecer os grupos experimentais foi utilizado como valor de ponto de corte proteínas séricas totais (PST) da ordem de 4,5g/dL, considerando-se ausência de desidratação, portanto, a ocorrência de FTIP era diagnosticada para animais que apresentassem PST $\leq 4,5 \mathrm{~g} / \mathrm{dL}$ (FEITOSA et al. $\left.{ }^{7}\right)$ estes animais constituiram o grupo 1 (G1) e os cordeiros com valores de PST $>4,5 \mathrm{~g} / \mathrm{Dl}$ o grupo 2 (G2), ou seja sem FTIP.

Os cordeiros foram acompanhados em seis momentos: entre 24-72 horas após o nascimento (M1); aos 7 dias de idade (M2); aos 15 dias (M3), 30 dias (M4), 60 dias (M5) e 90 dias de vida (M6). Em todos os momentos experimentais foi realizada avaliação física segundo Pugh $^{15}$ e colheita de sangue por meio da punção da veia jugular após tricotomia e assepsia do local. Foram utilizadas agulhas descartáveis (25x8), acopladas a canhão adaptador, e tubos estéreis a vácuo (Becton - Dixen, Vacutainer System, NJ) com e sem anticoagulante (EDTA). As amostras de sangue com anticoagulante (EDTA) foram utilizadas para avaliação do hemograma, e as sem anticoagulante, para obtenção de soro sanguíneo, mantido sob abrigo da luz e congelado a $-20{ }^{\circ} \mathrm{C}$, para determinação das proteínas séricas totais e seu fracionamento eletroforético.

O hemograma foi realizado como padronizado por Birgel ${ }^{16}$, no Laboratório de Análises Clínicas do Centro de Desenvolvimento da Pecuária (Escola de Medicina Veterinária - Universidade Federal da Bahia). A proteína sérica total foi determinada pelo método colorimétrico do biureto utilizandose kit comercial, proposto por Gornall, Bardwaill e David $^{8}$. A leitura foi realizada em espectofotômetro utilizando-se comprimento de onda de 550nm. As determinações da Proteína Sérica Total (PST) foram realizadas no Laboratório de Patologia Clínica do Hospital Veterinário da UNIME (União Metropolitana de Educação e Cultura). A separação das frações proteicas foi realizada por eletroforese 
em gel de agarose (Celmgel), utilizando-se tampão Tris $\mathrm{pH} 9,5 \pm 0,2$. As placas de gel de agarose foram coradas com solução de negro de amido a $0,2 \%$ e descoradas com ácido acético a 5\%, como descrito por Friedman'. A leitura e o cálculo do fracionamento eletroforético foram realizados em densitômetro a $520 \mathrm{~nm}$ segundo Canavessi et al. $^{18}$, com separação manual das várias frações proteicas (albumina, alfa, beta e gama globulinas). Estas determinações foram realizadas no Laboratório de Diagnóstico das Parasitoses dos Animais Domésticos da Escola de Medicina Veterinária da Universidade Federal da Bahia.

A análise estatística dos dados foi realizada com o auxílio do programa Statistica versão $6.0^{19}$. Todas as análises tiveram como referência $95 \%$ de confiança ( $\mathrm{p}$ $\leq 0,05)$, evidenciando um caráter significativo para as comparações efetuadas. Para os dados quantitativos, foram realizadas duas análises: a Prova de Wilcoxon, quando os dados eram dependentes e a Prova de Mann-Whitney, para dados independentes. Em cada momento foram comparados os valores médios dos dois grupos de animais (G1 e G2), obtendo-se ou não diferença estatisticamente significativa $(\mathrm{p} \leq 0,05)$. Foram realizados ensaios estatísticos para verificação de influência da falha da transferência da imunidade passiva, do sexo dos cordeiros e também do grau de sangue dorper nas variáveis do proteinograma.

\section{Resultados}

Dos 45 animais utilizados, $11(24,4 \%)$ tiveram proteinemia menor ou igual a $4,5 \mathrm{~g} / \mathrm{dL}$ às $24-72$ horas de vida, indicando que tiveram FTIP (G1) e 34 cordeiros $(75,6 \%)$ tiveram teores de proteínas séricas totais superiores a $4,5 \mathrm{~g} / \mathrm{dL}$, não apresentando a FTIP (G2). Os valores das proteínas totais e do perfil eletroforético de $24-72 \mathrm{~h}$ de vida até os 90 dias de idade dos animais de ambos os grupos são apresentados na tabela 1 . Não foi observada qualquer diferença estatisticamente significativa $(p \leq 0,05)$ influenciada pelo sexo ou grau de sangue, indicando homogeneidade dos indivíduos.

As concentrações de proteínas séricas totais e de suas frações eletroforéticas apresentaram valores significativamente maiores $(\mathrm{p}<0,05)$ às $24-72 \mathrm{~h}$ de vida no G2 quando comparados com os valores de G1, com exceção da fração betaglobulina-2. Aos sete dias, apenas a albumina apresentou diferença, sendo G2 maior que o G1. Aos 30 dias de idade, a concentração de PST do G1 foi superior que a do G2. No G1 o valor mais baixo da concentração de PST ocorreu aos 15 dias de idade, enquanto que no G2 a menor concentração de PST ocorreu aos 30 dias. A fração betaglobulina $1(\beta-1)$ apresentou concentração significativamente superior no grupo G2 $(\mathrm{p}<0,05)$ às $24-72 \mathrm{~h}$ após o nascimento. No entanto, nos demais momentos experimentais não houve diferenças significativas, porém foi observado um discreto aumento nos teores destas frações no G1, fazendo com que este grupo apresentasse valores médios ligeiramente superiores aos de G2 dos 7 aos 90 dias de idade.

A fração gamaglobulina apresentou concentrações superiores $(p<0,05)$ no grupo sem FTIP $(G 2)$ às 24-72h após o nascimento, porém, esta diferença não ocorreu nos demais momentos de análise. Nota-se que aos 15 dias de vida as concentrações de gamaglobulinas de G1 foram discretamente superiores às de G2 e esse comportamento se manteve até os 90 dias de idade.

\section{Discussão}

Adotando-se o critério proposto por Feitosa et al. ${ }^{7}$, no qual na ausência de desidratação, concentração de proteína sérica acima de $5 \mathrm{~g} / \mathrm{dL}$ indica transferência passiva bem sucedida, enquanto que valores inferiores a $4,5 \mathrm{~g} / \mathrm{dL}$ são considerados como de portadores da FTIP e valores entre 4,5 e 5,0g/dL são questionáveis. Registraram-se nesta pesquisa 11 
Tabela 1 - Valores médios expressos em g/dL da proteína sérica total (PST) e das frações proteicas separadas eletroforeticamente: albumina (ALB), a-globulina ( $\alpha), \beta 1$ - globulina $(\beta-1), \beta 2$-globulina $(\beta-2), \gamma$-globulina $(\gamma)$ de cordeiros com FTIP (G1) e sem FTIP (G2) no M1 (24-72h de vida), M2 (7 dias de idade), M3 (15 dias de idade), M4 (30 dias de idade), M5 (60 dias de idade), M6 (90 dias de idade). Santo Amaro da Purificação - BA - 2006

\begin{tabular}{|c|c|c|c|c|c|c|c|}
\hline & & $\begin{array}{c}\text { M1 } \\
(24-72 h)\end{array}$ & $\begin{array}{l}\text { M2 } \\
(7 d)\end{array}$ & $\begin{array}{c}\text { M3 } \\
(15 d)\end{array}$ & $\begin{array}{c}\text { M4 } \\
\text { (30d) }\end{array}$ & $\begin{array}{c}\text { M5 } \\
\text { (60d) }\end{array}$ & $\begin{array}{c}\text { M6 } \\
\text { (90d) }\end{array}$ \\
\hline \multirow{2}{*}{ PST } & G1 & $\begin{array}{c}3,94 \pm \\
0,36 \mathrm{~A}^{*}\end{array}$ & $\begin{array}{l}4,85 \pm \\
0,79 \mathrm{~A}\end{array}$ & $\begin{array}{l}4,84 \pm \\
0,54 \mathrm{~A}\end{array}$ & $\begin{array}{l}5,03 \pm \\
0,37 \mathrm{~A}\end{array}$ & $\begin{array}{l}4,85 \pm \\
0,17 \mathrm{~A}\end{array}$ & $\begin{array}{l}5,21 \pm \\
0,51 \mathrm{~A}\end{array}$ \\
\hline & G2 & $\begin{array}{l}6,12 \pm \\
0,44 \mathrm{~B}\end{array}$ & $\begin{array}{l}5,47 \pm \\
0,99 \mathrm{~A}\end{array}$ & $\begin{array}{l}4,94 \pm \\
0,53 \mathrm{~A}\end{array}$ & $\begin{array}{l}4,88 \pm \\
0,39 \mathrm{~A}\end{array}$ & $\begin{array}{l}5,00 \pm \\
0,36 \mathrm{~A}\end{array}$ & $\begin{array}{l}5,24 \pm \\
0,43 \mathrm{~A}\end{array}$ \\
\hline \multirow{2}{*}{ ALB } & G1 & $\begin{array}{l}1,77 \pm \\
0,36 \mathrm{~A}\end{array}$ & $\begin{array}{l}2,23 \pm \\
0,56 \mathrm{~A}\end{array}$ & $\begin{array}{l}2,35 \pm \\
0,51 \mathrm{~A}\end{array}$ & $\begin{array}{l}2,56 \pm \\
0,68 \mathrm{~A}\end{array}$ & $\begin{array}{l}2,40 \pm \\
0,51 \mathrm{~A}\end{array}$ & $\begin{array}{l}2,50 \pm \\
0,40 \mathrm{~A}\end{array}$ \\
\hline & G2 & $\begin{array}{l}2,69 \pm \\
0,16 \mathrm{~B}\end{array}$ & $\begin{array}{l}2,70 \pm \\
0,45 \mathrm{~B}\end{array}$ & $\begin{array}{l}2,44 \pm \\
0,38 \mathrm{~A}\end{array}$ & $\begin{array}{l}2,56 \pm \\
0,38 \mathrm{~A}\end{array}$ & $\begin{array}{l}2,64 \pm \\
0,36 \mathrm{~A}\end{array}$ & $\begin{array}{l}2,77 \pm \\
0,34 \mathrm{~A}\end{array}$ \\
\hline \multirow{2}{*}{$\alpha$} & G1 & $\begin{array}{l}0,16 \pm \\
0,09 \mathrm{~A}\end{array}$ & $\begin{array}{l}0,28 \pm \\
0,10 \mathrm{~A}\end{array}$ & $\begin{array}{l}0,36 \pm \\
0,12 \mathrm{~A}\end{array}$ & $\begin{array}{l}0,41 \pm \\
0,11 \mathrm{~A}\end{array}$ & $\begin{array}{l}0,37 \pm \\
0,11 \mathrm{~A}\end{array}$ & $\begin{array}{l}0,38 \pm \\
0,09 \mathrm{~A}\end{array}$ \\
\hline & G2 & $\begin{array}{l}0,33 \pm \\
0,16 \mathrm{~B}\end{array}$ & $\begin{array}{l}0,34 \pm \\
0,11 \mathrm{~A}\end{array}$ & $\begin{array}{l}0,40 \pm \\
0,11 \mathrm{~A}\end{array}$ & $\begin{array}{l}0,39 \pm \\
0,10 \mathrm{~A}\end{array}$ & $\begin{array}{l}0,39 \pm \\
0,10 \mathrm{~A}\end{array}$ & $\begin{array}{l}0,37 \pm \\
0,11 \mathrm{~A}\end{array}$ \\
\hline \multirow{2}{*}{$\beta-1$} & G1 & $\begin{array}{l}0,51 \pm \\
0,16 \mathrm{~A}\end{array}$ & $\begin{array}{l}0,69 \pm \\
0,09 \mathrm{~A}\end{array}$ & $\begin{array}{l}0,77 \pm \\
0,14 \mathrm{~A}\end{array}$ & $\begin{array}{l}0,78 \pm \\
0,14 \mathrm{~A}\end{array}$ & $\begin{array}{l}0,71 \pm \\
0,12 \mathrm{~A}\end{array}$ & $\begin{array}{l}0,76 \pm \\
0,13 \mathrm{~A}\end{array}$ \\
\hline & G2 & $\begin{array}{l}0,79 \pm \\
0,22 \mathrm{~B}\end{array}$ & $\begin{array}{l}0,73 \pm \\
0,16 \mathrm{~A}\end{array}$ & $\begin{array}{l}0,74 \pm \\
0,11 \mathrm{~A}\end{array}$ & $\begin{array}{l}0,75 \pm \\
0,14 \mathrm{~A}\end{array}$ & $\begin{array}{l}0,70 \pm \\
0,12 \mathrm{~A}\end{array}$ & $\begin{array}{l}0,69 \pm \\
0,18 \mathrm{~A}\end{array}$ \\
\hline \multirow{2}{*}{$\beta-2$} & G1 & $\begin{array}{l}0,25 \pm \\
0,14 \mathrm{~A}\end{array}$ & $\begin{array}{l}0,41 \pm \\
0,28 \mathrm{~A}\end{array}$ & $\begin{array}{l}0,38 \pm \\
0,12 \mathrm{~A}\end{array}$ & $\begin{array}{l}0,45 \pm \\
0,24 \mathrm{~A}\end{array}$ & $\begin{array}{l}0,44 \pm \\
0,17 \mathrm{~A}\end{array}$ & $\begin{array}{l}0,43 \pm \\
0,10 \mathrm{~A}\end{array}$ \\
\hline & G2 & $\begin{array}{l}0,33 \pm \\
0,16 \mathrm{~A}\end{array}$ & $\begin{array}{l}0,40 \pm \\
0,14 \mathrm{~A}\end{array}$ & $\begin{array}{l}0,38 \pm \\
0,14 \mathrm{~A}\end{array}$ & $\begin{array}{l}0,39 \pm \\
0,10 \mathrm{~A}\end{array}$ & $\begin{array}{l}0,39 \pm \\
0,09 \mathrm{~A}\end{array}$ & $\begin{array}{l}0,38 \pm \\
0,18 \mathrm{~A}\end{array}$ \\
\hline \multirow{2}{*}{$\Gamma$} & G1 & $\begin{array}{l}1,25 \pm \\
0,57 \mathrm{~A}\end{array}$ & $\begin{array}{l}1,24 \pm \\
0,63 \mathrm{~A}\end{array}$ & $\begin{array}{l}0,98 \pm \\
0,45 \mathrm{~A}\end{array}$ & $\begin{array}{l}0,83 \pm \\
0,28 \mathrm{~A}\end{array}$ & $\begin{array}{l}0,93 \pm \\
0,23 \mathrm{~A}\end{array}$ & $\begin{array}{l}1,15 \pm \\
0,38 \mathrm{~A}\end{array}$ \\
\hline & G2 & $\begin{array}{l}1,98 \pm \\
0,98 \mathrm{~B}\end{array}$ & $\begin{array}{l}1,29 \pm \\
0,51 \mathrm{~A}\end{array}$ & $\begin{array}{l}0,97 \pm \\
0,36 \mathrm{~A}\end{array}$ & $\begin{array}{l}0,78 \pm \\
0,24 \mathrm{~A}\end{array}$ & $\begin{array}{l}0,88 \pm \\
0,26 \mathrm{~A}\end{array}$ & $\begin{array}{l}1,02 \pm \\
0,27 \mathrm{~A}\end{array}$ \\
\hline
\end{tabular}

*Letras iguais na mesma coluna, em cada variável, não diferem entre si pela Prova de Mann - Whitney a $5 \%$ de significância

$(24,4 \%)$ animais acometidos por FTIP. No entanto, há enorme discordância de opiniões entre autores quanto à definição de um valor ideal de proteína total e também de outros parâmetros que avaliassem com precisão a ocorrência da FTIP. Observando os valores individuais de proteínas totais no soro sanguíneo às 24-72h propostos por outros autores ${ }^{2,7,20,21}$ esses valores poderiam ser diferentes. Adotando-se os critérios de Naylor et al. $^{20}$, que consideraram como portadores de FTIP bezerros que possuíam concentração de proteína sérica total menor ou igual a $6,0 / \mathrm{dL}$ no presente trabalho seriam considerados $30(66,6 \%)$ animais acometidos pela FTIP. No caso do emprego dos valores de referência utilizados por Heath ${ }^{21}$, proteína sérica mínima de $5,5 \mathrm{~g} / \mathrm{dL}$ para uma proteção satisfatória contra agentes patogênicos, 21 (46,6\%) cordeiros seriam considerados sem terem recebido o aporte adequado de imunoglobulinas maternais, correspondendo ao grupo com FTIP. Costa et al. ${ }^{2}$ utilizaram o valor de proteína sérica total de $5,0 \mathrm{~g} / \mathrm{dL}$ como limite mínimo para a não ocorrência de FTIP em bezerros. Com esta taxa de corte, os índices de FTIP seriam de 17 animais, ou seja, 37,8\%.

No presente trabalho, as modificações observadas no perfil eletroforético durante desenvolvimento etário foram basicamente em consequência das variações de taxas da fração gamaglobulina, o que está de acordo com as observações de Feitosa et al. ${ }^{7}$, verificando-se que logo após o nascimento as proteínas se apresentam com valores mínimos devido aos baixos teores das globulinas. No entanto, após a ingestão de colostro, há um rápido aumento 
da fração gamaglobulina resultante da absorção das imunoglobulinas colostrais.

As proteínas séricas, bem como as suas frações eletroforéticas, apresentaram-se superiores $(\mathrm{p}<0,05)$ às 24-72 horas após o nascimento no G2, exceto para a fração $\beta 2$. Porém, estas diferenças não foram constatadas nos demais momentos de análise. Estes achados concordam com os encontrados por Costa et $\mathrm{al}^{2}$, que observaram que os bezerros acometidos por FTIP apresentaram uma recuperação das concentrações de proteínas e frações eletroforéticas. Contudo, esta compensação foi observada aos 60 dias de idade. No presente trabalho a compensação ocorreu logo aos sete dias, quando as diferenças deixaram de ser significativas, e já aos 15 dias de idade o grupo G1 apresentou valores discretamente superiores aos de G2. Este comportamento também foi constatado por Moraes et al. ${ }^{22}$ que verificaram que os bezerros com FTIP $(14,5 \%)$ apresentaram quantidades significativamente menores de imunoglobulinas até os 56 dias de idade. Após este período de vida não houve diferença significativa entre os grupos com e sem FTIP. Tal fato pode ser justificado por uma produção endógena de imunoglobulinas que se inicia mais cedo em animais que não consumiram colostro ${ }^{7}$, o que provavelmente se dá porque a condição de hipogamaglobulinemia torna os animais mais susceptíveis aos estímulos antigênicos do ambiente, logo este grupo de animais responde mais precocemente, produzindo suas próprias imunoglobulinas. Entretanto, a transferência de concentrações adequadas de imunoglobulinas confere boa proteção imunológica aos animais frente aos estímulos patogênicos neste período. Pauletti et al. ${ }^{23}$ verificaram que nos animais com baixa aquisição inicial de anticorpos houve uma produção de imunoglobulinas mais precoce. Por sua vez, nos animais com concentrações adequadas de anticorpos há uma fase de catabolismo prolongada das imunoglobulinas e um início mais tardio da síntese endógena de anticorpos. Feitosa et al. ${ }^{7}$, destacam ainda que a produção de imunoglobulinas endógenas parece ser mais acelerada em animais hipogamaglobulinêmicos, verificandose assim a interferência de elevadas concentrações séricas de imunoglobulinas obtidas passivamente, que retardam o momento do início da sua produção ativa. Tais observações também foram realizadas por Borges et al. ${ }^{24}$ que verificaram o comportamento do proteinograma de 32 bezerros holandeses subdivididos em quatro grupos com diferentes métodos de ingestão de colostro e observaram que o grupo de bezerros privados de colostro (hipogamaglobulinêmicos) chegou aos 90 dias de idade com a fração gamaglobulina com maior magnitude (porém não significativa) que o dos bezerros que ingeriram colostro diretamente das vacas.

\section{Conclusões}

A ocorrência de FTIP em rebanho ovino, esteve presente em $24,4 \%$ dos cordeiros avaliados. Observouse também que os animais hipogamaglobulinêmicos apresentaram baixos teores de proteínas séricas e de todas as suas frações eletroforéticas às 24-72 horas após o nascimento, no entanto, houve uma rápida recuperação de suas taxas após os sete dias de idade.

\section{Agradecimentos}

A toda equipe da UFBA e UNIME que auxiliaram na realização das etapas do experimento. Ao Sr. André Teixeira pela cessão da propriedade e dos animais, a CAPES pela bolsa de estudos concedida. 


\section{Referências}

1. FERES, F. C.; LOMBARDI, A. L.; BARBOSA, T. S.; MENDES, L. C. N.; PEIRÓ, J. R.; CADIOLI, F. A.; PERRI, S. H. V. Avaliação da imunidade passiva em cordeiros com até 30 dias de idade. Brazilian Journal Veterinária Research Animal Science, São Paulo, v. 47, n. 3, p. 231-236, 2010.

2. COSTA, J. N.; PEIXOTO, A. P. C.; KOHAYAGAWA, A.; SOUZA, T. S. Proteinograma sérico de bezerras da raça Holandesa do nascimento aos 150 dias de idade. Revista Brasileira de Saúde e Produção Animal, v. 8, n. 4, p. 267-275, 2007.

3. DONOVAN, G. A.; DOHOO, I. R.; MONTGOMERY, D. M.; BENNETT, F. L. Associations between passive immunity and morbidity and mortality in dairy heifers in Florida, U.S.A. Preventive Vetrinary Medicine, v. 34, n. 1, p. 31-46, 1998.

4. WEAVER, D. M. Passive transfer of colostral immunoglobulins in calves. Journal of Veterinary Internal Medicine, v. 14, n. 6, p. $569-577,2000$.

5. BEKELE, T.; OTESILE, E. B.; KASALI, O. B. Influence of passively acquired colostral immunity on neonatal lamb mortality in Ethiopian highland sheep. Small Ruminant Research, Amsterdam, v. 9, n. 3, p. 209-215, 1992.

6. SIMÕES, S. V. D.; COSTA, R. G.; SOUZA, P. M. de; MEDEIROS, A. N. de; VILAR, A. L. T. Imunidade passiva, morbidade neonatal e desempenho de cabritos em diferentes manejos de colostro. Pesquisa Veterinária Brasileira, v. 25, n. 04, p. 219-224, 2005.

7. FEITOSA, F. L. F.; BIRGEL, E. H.; MIRANDOLA, R. M. S.; PERRI, S. H. V. Diagnóstico de falha de transferência de imunidade passiva em bezerros através da determinação de proteína total e de suas frações eletrofroréticas, imunoglobulinas $\mathrm{G}$ e $\mathrm{M}$ e da atividade da gama glutamil transferase no soro sanguíneo. Ciência Rural, v. 31, n. 2, p. 251-255, 2001.

8. GORNALL, A. G.; BARDWAILL, C. J.; DAVID, M. M. Determination of serum protein by means of biuret reaction. Journal of Biological Chemistry, v. 177, n. 2, p. 751-766, 1949.

9. FRIEDMAN, H. S. A standardized procedure for serum protein electrophoresis on cellulose acetate membrane strips. Clínica Chimica Acta, v. 6, p. 775-781, 1961.

10.GARRY, F.; ALDRIDGE, B.; ADAMS, R. Role of colostral transfer in neonatal calf management: current concepts in diagnosis. Compendium Continnuing Education, v. 15, n. 8 , p. 1167-1174, 1993.

11.TURQUINO, C. F.; FLAIBAN, K. K. M. C.; LISBÔA, J. A. N. Transferência de imunidade passiva em cordeiros de corte manejados extensivamente em clima tropical. Pesquisa Veterinária Brasileira, v. 31, n. 3, p. 199-205, 2011.
12.GIRÃO, R. N.; MEDEIROS, L. P.; GIRÃO, E. S. Mortalidade de cordeiros da raça Santa Inês em um núcleo de melhoramento no estado do Piauí. Ciência Rural, v. 28, n. 4, p. 641-645, 1998.

13.NÓBREGA JR., J. E.; RIET-CORREA, F.; NÓBREGA, R. S.; MEDEIROS, J. M. de; VASCONCELOS, J. S. de; SIMÕES, S. V. D.; TABOSA, I. M. Mortalidade perinatal de cordeiros no semiárido da Paraíba. Pesquisa Veterinária Brasileira, v. 25, n. 3, p. 171-178, 2005.

14.CHAARANI, B.; ROBINSON, R. A.; JHONSON, D. W. Lamb mortality in Meknes province (Morocco). Preventive Veterinary Medicine, Amsterdam, v. 10, n. 4, p. 283-298, 1991.

15.PUGH, D. G. Artrite-encefalite caprina. In: Clínica de caprinos e ovinos. São Paulo: Roca Ltda, 2004. p. 269-271.

16. BIRGEL, E. H. Hematologia clínica veterinária, In: BIRGEL, E. H.; BENESI, F. J. Patologia clínica veterinária. São Paulo: Sociedade Paulista de Medicina eterinária, 1982. p. 2-49.

17.GORDON, H. M.; WHITLOCK, H. V. A new technique for counting nematode eggs in sheep faeces. Journal of Council Science Industry Research, v. 12, n. 1, p. 50-52, 1939.

18. CANAVESSI, A. M. O.; CHIACCHIO, S. B.; SARTORI, R.; CURY, P. R. Valores do perfil eletroforético das proteínas séricas de bovinos da raça Nelore (Bos indicus) criados na região de Botucatu, São Paulo: influência dos fatores etários e sexuais. Arquivos do Instituto Biológico, v. 67, n. 1, p. 9-17, 2000.

19.STATISTICA version 6.0. Data analysis software system. Tulsa: StatSoft, Inc., 2001.

20. NAYLOR, J. M.; KRONFELD, D. S.; BECH-NIELSEN, S.; BARTHOLOMEW, R. C. Plasma total protein measurement for prediction of disease and mortality in calves. Journal of the American Veterinary Medical Association, v. 171, n. 7, p. 635-638, 1997.

21. HEATH, S. E. Neonatal diarrhea in calves: investigation of herd managenment practices. Compendium on Continuing Education for the Practing Veterinarian, v. 14, n. 3, p. 385-395, 1992.

22.MORAES, M. P.; WEIBLEN, R.; SILVA, A. M.; TOBIAS, F. L. Evolução da imunidade passiva em fêmeas bovinas da raça holandesa. Ciência Rural, v. 27, n. 3, p. 435-440, 1997.

23. PAUlETTI, P.; MACHADO NETO, R.; PACKER, I. U.; D'ARCE, R. D.; BESSI, R. Quality of colostral passive immunity and pattern of serum protein fluctuation in newborn calves. Scientia Agricola, Piracicaba, v. 60, n. 3, p. 453-456, 2003.

24.BORGES, A. S.; FEITOSA, F. L. F.; BENESI, F. J.; BIRGEL, E. H.; MENDES, L. C. N. Influência da forma de administração e da quantidade fornecida de colostro sobre a concentração de proteína total e de suas frações eletroforéticas no soro sanguíneo de bezerros da raça Holandesa. Arquivo Brasileiro de Medicina Veterinária e Zootecnia, v. 53, n. 5, p. 629-634, 2001. 